\title{
Da família na escola à escola no lar: notas sobre uma polêmica em curso
}

\author{
From families at school to schooling at home: notes on a current \\ debate
}

\section{De la familia en la escuela a la escuela en el hogar: apuntes sobre una controversia}

\author{
Maria Eulina Pessoa de Carualho' \\ Universidade Federal da Paraíba, Departamento de Habilitação Pedagógica e do Programa \\ de Pós-Graduação em Educação, Professora titular. \\ http://orcid.org/0000-0002-2947-5814
}

Resumo: Com base em pesquisa bibliográfica e documental, o texto examina contextos, conceitos e discursos envolvidos no debate dos projetos "escola sem partido" e "educação domiciliar", que confundem as funções educativas da família e da escola e atentam contra o sentido da educação pública e a profissionalidade docente. Para explicitar esses argumentos, no marco das relações família-escola e da emergência de recentes tendências neoconservadoras e neoliberais, este artigo atualiza a movimentação dos projetos no legislativo federal, analisa os textos das últimas versões e revisa literatura acadêmica recente. Constatou-se que, enquanto o primeiro projeto é uma tentativa de controle do currículo escolar e da atuação docente por um grupo de famílias, o segundo pretende legitimar a evasão das crianças do espaço público da escola para receberem toda a educação em casa, ignorando a profissionalidade docente. Esse último ponto é ilustrado pelo debate entre internautas quando do lançamento do mais recente projeto de educação domiciliar.

Palavras-chave: Escola sem partido. Educação domiciliar. Relações escola-família. Educação pública. Profissionalidade docente.

Abstract: Based on bibliographical and documentary research, this text examines contexts, concepts and discourse involved in the debate of "school without party" and "homeschooling" policy calls, both of which mistake the educational functions of families and schools and attack the meaning of public education and the teaching profession. In order to put forth these arguments, at the core of familyschool relations and the emergence of recent neo-conservative and neo-liberal trends, it updates the related federal legislative projects, analyses the latest drafts' texts, and reviews recent academic

PhD em Currículo, Ensino e Política Educacional pela Michigan State University, USA; Pós-doutora pela Universidade de Valencia, Espanha. 
literature. It concludes that, while the first project is an attempt to control schools' curricula and teachers' actions by a group of families, the latter intends to legitimize children evasion from the public space of schools, ignoring the teaching profession. This last point is illustrated by the debate among internet users upon the launch of the most recent homeschooling project.

Keywords: "School without party". Homeschooling. Family-school relations. Public education. Teaching profession.

Resumen: Con base en investigación bibliográfica y documental, el texto examina contextos, conceptos y discursos involucrados en el debate de dos proyectos "escuela sin partido" e "educación en el hogar", que confunden las funciones educativas de la familia y de la escuela y dañan el significado de la educación pública y la profesionalidad de la enseñanza. Para aclarar esos argumentos, en el marco de las relaciones familia-escuela y del surgimiento reciente de tendencias neoconservadoras y neoliberales, actualiza el movimiento de los proyectos en la legislatura federal, analiza sus últimas versiones y revisa literatura académica reciente. Señala mientras el primer proyecto es un intento de control del currículum escolar y de la enseñanza por un grupo de familias, el segundo proyecto pretende legitimar la deserción de los niños del espacio público de la escuela para recibir toda la formación en el ámbito familiar, ignorando la profesionalidad docente. Ese último punto es ilustrado en el debate de internautas cuando se presentó el último proyecto de educación en el hogar.

Palabras claves: "Escuela sin partido". Educación en el hogar. Relaciones escuela-familia. Educación pública. Profesionalidad de la enseñanza.

Recebido em 13 de outubro de 2019 Aceito em 7 de maio de 2020 Publicado em 09 de junho de 2020

\section{INTRODUÇÃO}

Este texto aborda a polêmica em torno de dois projetos de lei (PL) recentes em tramitação no legislativo federal: "escola sem partido" e "educação domiciliar", que expressam a emergência de tendências neoconservadoras e neoliberais no cenário sociopolítico brasileiro. 0 primeiro é sobre a ingerência da família na escola, de fato, a tentativa de algumas famílias de controlar o currículo escolar e censurar a atuação docente; o segundo contesta a escolarização compulsória e reivindica a liberdade da família de ensinar o equivalente ao currículo escolar em casa. Cada um teve várias versões precedentes e concomitantes (retiradas, reapresentadas e apensadas), que não serão consideradas aqui, restringindose a análise aos PL n. 246/2019 e PL n. 258/2019 ("escola sem partido") (CÂMARA DOS 
DEPUTADOS, 2019b, 2019c) e PL n. 3.261/2015 e PL n. 2401/2019 ("educação domiciliar") (CÂMARA DOS DEPUTADOS, 2015, 2019c).

"Escola sem partido" e "educação domiciliar" são construções discursivas/ retóricas - ancoradas nas formaç̃̃es discursivas (termo foucaultiano) ou ideologias (termo da teoria crítica) mais amplas do neoliberalismo e do neoconservadorismo - que expressam visões de mundo (e especificamente de escola) e estilos de vida (particularmente familiar), evocando, afirmando e negando significados e valores de políticas e práticas sociais e educativas. De acordo com Giddens e Sutton (2017, p. 7), o conceito de discurso, originado na Linguística, é de interesse de várias disciplinas, referindo-se ao "modo de falar e pensar sobre um assunto, unido por princípios comuns", objetivando "estruturar a compreensão e as ações das pessoas sobre determinado assunto." A comunicação verbal ou escrita, em diversos formatos e contextos, constitui "atos de discurso" que influenciam e intervêm na realidade social, segundo John $L$. Austin, e funcionam como práticas discursivas com efeitos de poder, segundo Michel Foucault.

Assim, existe uma relação complexa que envolve circulação de influências (culturais, ideológicas), disputa interpretativa e competência linguística/argumentativa (retórica) entre discursos cotidianos sobre os problemas sociais e educacionais, argumentos politicos intencionalmente pautados (por movimentos e grupos sociais) e sua tradução em políticas públicas. Em contextos formais e informais, os discursos descrevem e prescrevem significados, valores e normas, influenciando a percepção e o debate públicos, estabelecendo, assim, discursos dominantes, que podem ser contestados por discursos alternativos, na luta por hegemonia cultural. Nos casos que interessam aqui, estão sendo contestadas a educação pública e a escolarização compulsória, a liberdade de cátedra e o currículo multicultural. 0 ideário do "escola sem partido", segundo Frigotto (2017), inviabiliza a escola pública como lugar de formação humana e convivio social; e a "educação domiciliar simplesmente nega a escola pública como esse lugar. Ademais, ambos os projetos - e em especial o de educação domiciliar - ignoram a profissionalidade docente, entendida como ação de ensinar, que envolve tanto um conhecimento profissional específico, quanto o desenvolvimento de uma identidade profissional, expressando modos próprios de ser e de atuar (competências) sóciohistoricamente contextualizados na escola (GORZONI; DAVIS, 2017, p. 1411).

A análise de políticas educacionais, das quais as leis são um dos instrumentos, considera texto e contexto, bem como grupos de interesse e impactos sociais. Aqui se pretende apenas uma aproximação ao debate das propostas "escola sem partido" e "educação domiciliar". Sendo o termo discurso "empregado para se referir a todas as formas de fala e textos", gerados em situação natural (conversações), em entrevistas e "textos escritos de todo tipo" (GILL, 2010, p. 247), os textos analisados aqui são os referidos projetos de lei, textos acadêmicos que fazem sua crítica, textos de sites de organizações de advocacia 
que os defendem, textos de jornais e textos teclados de falas de internautas em reação ao último projeto de educação domiciliar.

Portanto, com base em fontes bibliográficas e documentais (acadêmicas, legislativas, jornalísticas, digitais), este texto explora contextos, conceitos e discursos envolvidos no debate atual dos projetos "escola sem partido" e "educação domiciliar". Na segunda seção, apresenta sua movimentação no legislativo federal e elementos do contexto social e político nacional e internacional. Na terceira seção, examina os textos de suas últimas versões (PL n. 246/2019 e PL n. 2.401/2019) (CÂMARA DOS DEPUTADOS, 2019b, 2019d), problematizando a ingerência da família na escola e o retorno da escola ao lar. Na quarta seção, confronta a retórica da educação domiciliar e a realidade, segundo os discursos de internautas que reagem a uma reportagem de jornal, quando do lançamento do mais recente projeto de educação domiciliar em abril de 2019 (PL n. 2.401/2019) (CÂMARA DOS DEPUTADOS, 2019d). Finalmente, na quinta seção, argumenta que tais projetos confundem as funções educativas da família e da escola e atentam contra o sentido da educação pública e a profissionalidade docente, apontando alguns de seus aspectos problemáticos e contradições.

\section{O CONTEXTO DOS PROJETOS “ESCOLA SEM PARTIDO” E "EDUCAÇÃO DOMICILIAR"}

Assiste-se atualmente a uma polêmica impulsionada pelos projetos de lei (PL) "escola sem partido" e "educação domiciliar", que têm como voz ruidosa o movimento fundamentalista cristão, representado no Congresso Nacional e no Ministério da Mulher, Família e Direitos Humanos (MMFDH). São projetos que combinam um viés neoconservador, que acentua a educação moral, sexual e religiosa, com um viés neoliberal, que defende a liberdade de escolha educacional da família, rejeitando a diversidade cultural e o pluralismo ideológico e político na convivência escolar, antessala do mundo público.

0 PL n. 246/2019, da deputada Bia Kicis (PSL/DF) (CÂMARA DOS DEPUTADOS, 2019b), apresentado em 4 de fevereiro de 2019 (apensado ao PL n. 867/2015, do Deputado Izalci Lucas (PSDB/DF)), institui o "Programa Escola sem Partido". Analogamente, o PL n. 258/2019, do deputado Pastor Eurico - PATRI/PE (CÂMARA DOS DEPUTADOS, 2019c), apresentado em 4 de fevereiro de 2019 (apensado ao PL n. 7.180/2014, do deputado Erivelton Santana (PATRI/BA)), pretende dispor "sobre o direito dos alunos de aprender sem ideologia político-partidária" e "sobre a conduta dos professores na transmissão dos conteúdos", propondo a inclusão 
no art. $3^{\circ}$ da LDB2 (Lei n. 9.394/1996) do "respeito às convicções do aluno, de seus pais ou responsáveis, dando precedência aos valores de ordem familiar sobre a educação escolar nos aspectos relacionados à educação moral, sexual e religiosa", barrando "a inserção de questões relativas à ideologia de gênero no âmbito escolar." (CÂMARA DOS DEPUTADOS, 2019c).

No final de 2018, o PL n. 7.180/14 (CÂMARA DOS DEPUTADOS, 2014) havia sido arquivado por falta de consenso, graças à oposição liderada pela deputada Erika Kokay (PT/ DF) (CÂMARA DOS DEPUTADOS, 2018b). Segundo o relator, deputado Flavinho - PSC/SP, o projeto visava combater "o avanço maldito da ideologia de gênero" que vem destruindo "a inocência das crianças"; já o deputado Alan Rick (DEM/AC) alegou, sem evidência empírica, que o projeto combateria abusos contra alunos perseguidos e doutrinados por professores. No Senado Federal, o PLS 193/2016 (BRASL, 2016), também denominado Projeto Escola sem Partido, proposto pelo então senador Magno Malta (PR/ES), havia sido retirado pelo autor em 21 de novembro de 2017, após parecer do senador Cristovam Buarque (PPS/DF) recomendando sua rejeição. Paralela e articuladamente, projetos de lei similares foram a apresentados em Assembleias Legislativas Estaduais e Câmaras Municipais Brasil afora.

Quanto à educação domiciliar, o deputado federal Eduardo Bolsonaro (PSL/SP) apresentou o PL n. 3.261/2015 (CÂMARA DOS DEPUTADOS, 2015), que sintetizava tentativas anteriores de autorizar o ensino domiciliar na educação básica para menores de 18 anos, alterando dispositivos da LDB e do Estatuto da Criança e do Adolescente (ECA) (Lei n. 8.069/1990). Assim, os pais ou responsáveis poderiam matricular os(as) filhos(as) em escola optando pelo regime presencial (com frequência escolar regular) ou pelo regime de ensino domiciliar (com frequência restrita ao calendário de avaliações). Registra-se, também, o PL n. 10.185/2018 (CÂMARA DOS DEPUTAD0S, 2018a) do deputado Alan Rick (DEM/AC), arquivado em 31 de janeiro de 2019, que propunha alteração no art. 23 da LDB para admitir "a educação básica domiciliar, sob a responsabilidade dos pais ou tutores responsáveis pelos estudantes, observadas a articulação, supervisão e avaliação periódica da aprendizagem pelos órgãos próprios dos sistemas de ensino." (CÂMARA DOS DEPUTADOS, 2018a).

Em 11 de abril de 2019 foi anunciado novo PL para regulamentar a educação domiciliar no Brasil pelo MMFDH e assinado pelo Presidente Jair Bolsonaro em evento sobre os 100 dias de governo. Em 9 de abril de 2019, Damares Alves, titular do MMFDH e Abraham Weintraub, titular do Ministério da Educação (MEC), enviaram minuta de Medida Provisória (EMl n. 00019/2019) ao Presidente da República, solicitando urgência na regulamentação da educação domiciliar. O PL n. 2.401/2019 (CÂMARA DOS DEPUTAD0S, 2019c), enviado à Câmara dos Deputados

Alegando doutrinação ideológica nas escolas do Pais, tais projetos buscam alterar o art. $3^{\circ}$ da LDB, que estabelece os princípios do ensino, especificamente: "ll - liberdade de aprender, ensinar, pesquisar e divulgar a cultura, o pensamento, a arte e o saber [...] III - pluralismo de idéias e de concepções pedagógicas [...] IV - respeito à liberdade e apreço à tolerância." (BRASIL, 1996). 
pelo Poder Executivo em 7 de maio de 2019 (CÂMARA DOS DEPUTADOS, 2019a), garante aos pais a liberdade de optar entre a educação escolar ou domiciliar, bem como isonomia de direitos entre os estudantes em qualquer modalidade. Prevê cadastro obrigatório de estudantes em plataforma do Ministério da Educação, apresentação de plano pedagógico individual proposto por pais ou responsáveis legais, registro periódico das atividades pedagógicas do estudante, provas anuais de avaliação e certificação de aprendizagem (OLIVEIRA, 2019).

De um lado, tem-se a tentativa, de caráter totalitário, de controle da prática docente, do currículo escolar e de materiais didáticos e paradidáticos por um grupo de famílias que clamam pela "neutralidade política, ideológica e religiosa do Estado" ao mesmo tempo em que invocam seu suposto direito "a que seus filhos recebam a educação moral que esteja de acordo com suas próprias convicções" na escola pública, ${ }^{3}$ desconsiderando a diversidade cultural, social e familiar (CARVALHO, 2018, p. 66). De outro lado, tem-se a tentativa pretensamente liberal de escolha pela família da modalidade de educação a ser proporcionada a seus filhos(as), com a opção de que a recebam em casa, retirando-os(as) da convivência com os diferentes no espaço público da escola. A esses dois movimentos e projetos contrapõemse a concepção de formação para a cidadania como função precípua da educação pública e compromisso profissional docente, e os princípios constitucionais da liberdade de aprender e ensinar e do pluralismo de ideias e concepções pedagógicas na sala de aula.

Em seu site, o Programa Escola sem Partido, criado em 2004 e coordenado por Miguel Nagib, Procurador do Estado de São Paulo, apresenta-se em duas vertentes: uma do Projeto Escola Sem Partido, uma proposta de "lei contra o abuso da liberdade de ensinar", que torna obrigatória a afixação em todas as salas de aula do ensino fundamental e médio de um cartaz coibindo a atuação docente lespecificamente, "fazer a cabeça dos alunos sobre questões de natureza político-partidária, ideológica e moral"); e outra de "uma associação informal, independente, sem fins lucrativos e sem qualquer espécie de vinculação política, ideológica ou partidária" de "[...] pais preocupados com o grau de contaminação políticoideológica das escolas brasileiras, em todos os níveis: do ensino básico ao superior." (ESCOLA SEM PARTIDO, 2019). Assume explicitamente sua inspiração na associação estadunidense Nolndoctrination.org e oferece a governadores, prefeitos, deputados estaduais e vereadores modelos de anteprojetos de lei para serem replicados em estados e municípios.

0 movimento internacional de homeschooling é mencionado nos textos de justificativa dos PL de "educação domiciliar", e o PL n. 3.261/2015 (CÂMARA DOS DEPUTADOS, 
2015), por exemplo, argumenta que o homeschooling é legalizado em vários países. Por sua vez, a literatura acadêmica aponta o crescimento de sua demanda no contexto neoliberal atual, sobretudo na América do Norte, onde despontou na década de 1970 (BREWER; LUBIENSKY, 2017). Em países ricos, com escola em tempo integral há muito garantida e com população de alto nível de escolaridade, o homeschooling emergiu numa convergência de grupos díspares: fundamentalistas cristãos, de um lado, e contraculturais/libertários, de outro lado (BOSETT; VAN PELT, 2017). Foi na década de 1980 nos Estados Unidos, por exemplo, que se acirrou a disputa criacionismo ${ }^{4}$ versus evolucionismo nas escolas, capitaneada pelo primeiro grupo, similar à assumida aqui pelo Programa Escola sem Partido.

Em pesquisa na América do Norte, Aurini e Davies (2005) afirmam que o crescimento e legitimação ${ }^{5}$ do homeschooling foi acompanhado pela diversificação. Enquanto na década de 1970 o movimento era dominado por grupos de famílias fundamentalistas religiosas (que se opunham ao currículo escolar secular e valorizavam a autoridade familiar), ou adeptas de experiências de desescolarização ${ }^{6}$ (que criticavam o caráter massivo, burocrático e impessoal da escola estatal), mais recentemente "tem surgido uma variedade de subgrupos com diferentes finalidades, por exemplo, atender necessidades educativas especiais, apoiar identidades minoritárias, ou simplesmente buscar uma forma superior de educação." (AURIN); DAVIES, 2005, p. 462, tradução nossa). Os autores ressaltam que as organizações de homeschoolers (familias educadoras) no Canadá e nos Estados Unidos têm fundamentado suas reivindicações não mais em posições antisseculares ou antitecnocráticas, mas em noções de direitos individuais (ou direitos humanos), alinhando-se ao movimento school choice, ${ }^{7}$ que articula grupos dispares, e aproximando-se da cultura convencional (cultural mainstream), incluindo, também, grupos de esquerda e libertários, o que é corroborado por Ray (2015), um expoente do movimento nos Estados Unidos. ${ }^{8}$

Aurini e Davies (2005) situam o fenômeno no contexto do crescimento da educação privada, apontando-o como sua forma mais expressiva, associada à "cultura florescente da parentalidade intensiva, ${ }^{9}$ por combinar grandes investimentos de tempo e esforço com

4 Ver History... ([201-?]).

5 Homeschooling só obteve status legal nos Estados Unidos, em todos os 50 estados, em 1993 (AURINI; DAVIES, 2005). 0s estudantes educados em casa nesse País não passam de, aproximadamente, 4\% ou dois milhões, segundo Brewer e Lubienski (2017).

6 No original experimental 'unschoolers'.

70 movimento school choice reivindica alternativas à escola pública nos Estados Unidos (financiada pelo imposto predial e frequentada pelos estudantes residentes no distrito), como vouchers para frequência em escola fora do distrito de residência, charter schools, magnet schools, virtual schools, homeschooling e deduções no imposto de renda para gastos educacionais (SCHOOL CHOICE, ([201-2]).

8 Brian D. Ray fundou em 1990 e preside o National Home Education Research Institute (NHERI), uma organização sem fins lucrativos dedicada a "executar, avaliar e disseminar estudos e informação sobre homeschooling" nos Estados Unidos (https://www.nheri.org/).

9 Em inglês, intensive parenting. 0 termo parenting, ou child rearing, popularmente, significa estilo de criação de filhos(as). 
resultados altamente incertos." (AURINI; DAVIES, 2005, p. 461, tradução nossa). Contudo, nos Estados Unidos, País que tem a maior população estudantil educada em casa, embora não se conheça a parcela de familias religiosas envolvidas, segundo The International Center for Home Education Research (ICHER), ${ }^{10}$ um levantamento realizado em 2012 pelo National Center for Education Statistics apontou que $64 \%$ de pais/mães tinham como motivação fornecer "educação religiosa". Ainda segundo o ICHER, cristãos conservadores constituem o maior subgrupo dentre os praticantes de homeschooling nos Estados Unidos e o que exerce maior influência na percepção e discurso públicos (INTERNATIONAL CENTER FOR HOME EDUCATION RESEARCH, ([201-]).

Também no Brasil a motivação dos dois projetos em tela parece ser fortemente religiosa. Segundo Espinosa e Queiroz (2017, p. 49-50), eles podem ser situados em "uma poderosa teia de relações" em redes sociais e digitais, nacionais e internacionais, envolvendo organizações civis, religiosas e partidárias, que "combatem o ensinamento da teoria da evolução, a perspectiva de gênero ou temas relacionados com o multiculturalismo" e defendem o homeschooling, com destaque para os grupos neopentecostais." Tanto é que o PL n. 2.401/2019 (CÂMARA DOS DEPUTADOS, 2019c) foi encaminhado pela titular do MMFDH, que é pastora evangélica, oriunda da assessoria à bancada neopentecostal na Câmara dos Deputados.

De fato, em anos recentes, o homeschooling tem sido objeto de crescente interesse no Brasil, com o surgimento tanto de ações de estudantes e famílias reivindicando a educação domiciliar, quanto de processos contra pais que não matriculavam os filhos na escola. Em 2010 foi fundada a Associação Nacional de Educação Domiciliar (ANED), por iniciativa de um grupo de famílias de Belo Horizonte, MG. Sediada em Brasília, apresenta-se como instituição sem fins lucrativos, que tem como principal causa "a autonomia educacional da família", sua "liberdade e prioridade" na escolha da "modalidade de educação" ou "do gênero de instrução" a ser "ministrada/o aos seus filhos". Seus objetivos são "promover a defesa do direito da família à Educação Domiciliar no Brasil, através da representação coletiva dos seus associados" junto a autoridades e órgãos pertinentes; "promover ações de divulgação da Educação Domiciliar", em meios diversos; e "promover a integração e a cooperação entre as famílias educadoras, fornecendo o suporte necessário para esse fim."12

A questão chegou ao Supremo Tribunal Federal (STF) em 2015, na forma de recurso de uma estudante de Canela, RS, contra decisão do Tribunal de Justiça do Rio Grande do Sul (TJ-RS). Em 12 de setembro de 2018, o STF decidiu que a legislação vigente não permite que pais

10 Trata-se de um grupo de pesquisa internacional, não de uma organização de advocacia como a NHERI (http://www.icher. org/icher.html).

" E é exatamente com os Estados Unidos que têm afinidades os grupos neopentecostais brasileiros. Ver: Ribeiro ([201-?̣]).

12 Similar à NHERI, como instituição de advocacia. Ver: Associação Nacional de Educação Domiciliar (2019). 
tirem filhos(as) da escola para ensiná-los em casa, derrotando o voto favorável à autorização do ensino domiciliar (desde que atendidos requisitos mínimos) do relator Luís Roberto Barroso, que se valeu do entendimento de que a Constituição não o proíbe expressamente. ${ }^{13} \mathrm{Na}$ discussão, alguns ministros ressaltaram que o dever de educar implica cooperação entre Estado e família, sem exclusividade dos pais, e que a frequência escolar é necessária para garantir a convivência entre estudantes com diversidade de origens, valores e crenças; outros indicaram que o ensino domiciliar requereria regulamentação por lei que previsse a socialização da criança ou jovem e a avaliação do aprendizado (RAMALH0, 2018), o que se tratou de fazer via novos PL.

\section{DA INGERÊNCIA DA FAMÍLIA NA ESCOLA AO RETORNO DA ESCOLA AO LAR: CONCEITOS SUBJACENTES}

Consta na LDB, genericamente, que a educação, direito de todos(as), é dever da família e do Estado. Mas qual educação? Se há famílias que entendem que podem concretizar esse dever dispensando a escola ou regulação estatal, é preciso distinguir entre educação privada/familiar/doméstica e educação pública, com seu ideário próprio: o ensino da cultura formal e a construção da cidadania, em instituição especializada de educação compulsória. Assim, materializou-se o contrato social da educação moderna, que oferece "um terreno (supostamente neutro) para a aquisição de um conhecimento comum, secular, não familiar, que apagaria as distinções culturais e sociais ligadas à família, classe social, etnia e religião de origem, consolidando a nova ordem democrática." (CARVALHO, 2004b, p. 51).

Lembre-se que a escola surge, primeiro para as elites (camadas superiores e médias), como uma extensão da família, saindo do âmbito doméstico para o âmbito comunitário, como escola comum/privada. Depois se estatiza, se massifica e se organiza em sistemas de ensino incluindo a maioria da população pobre (camadas inferiores). Em todo caso, na ordem social contemporânea, a família delega a educação formal à escola, a qual, por meio de seus educadores, atua in loco parentis, não só encarregada do desenvolvimento individual, preparação para o trabalho e para a cidadania, mas da guarda das crianças de famílias cujos pais e mães majoritariamente trabalham fora de casa e têm, inclusive, reduzida participação na definição das políticas educacionais e práticas escolares (CARVALHO, 2004a, 2004b). Assim,

13 Ver Andrade (2017, p. 181) sobre o fato de que "não há no ordenamento jurídico brasileiro em vigor nenhuma norma jurídica que tenha como conteúdo ou objeto a Educação Domiciliar, seja em caráter permissivo ou proibitivo." Sendo a escolarização direito público subjetivo da criança e do adolescente, "é dever do Estado, de seus órgãos e agentes e dos pais ou responsáveis matricular as crianças a partir de 4 anos na escola e zelar por sua frequência no percentual legal de dias letivos." 
os responsáveis familiares não apenas transferem sua autoridade para o(a) professor(a), mas the delegam a função de educar no sentido de transmissão da cultura erudita que a maioria das famílias não detém. Nesse processo histórico, os professores - e logo as professoras se profissionalizaram por meio da qualificação especializada e organização sindical, embora ainda se trate de profissão desvalorizada e mal paga entre nós.

Lembre-se, também, que as politicas curriculares expressam consensos sobre conhecimento valioso (YOUNG, 2009) e são palco de disputas culturais/ideológicas/políticas e de controle social. Como se pode verificar nos textos dos PL "escola sem partido", um grupo minoritário de famílias, partidárias de certa religião e certa moral, pretende impor sua ideologia ao currículo comum na escola pública e controlar a prática docente, desautorizando o(a) professor(a) e sua atuação profissional.

0 PL n. 246/2019 (CÂMARA DOS DEPUTADOS, 2019b), da deputada Bia Kicis (PSL/DF), sintetiza todos os contrassensos dos projetos anteriores do Programa Escola sem Partido. De um lado, afirma os princípios da dignidade da pessoa humana; da neutralidade política, ideológica e religiosa do Estado; do pluralismo de ideias e de concepções pedagógicas; da liberdade de aprender, ensinar, pesquisar e divulgar o pensamento, a arte e o saber; e da liberdade de consciência e de crença (art. $1^{\circ}$ ). De outro lado, como explicita na sua justificação, postula que a liberdade de ensinar não se confunde com liberdade de expressão, e que esta não existe no "exercício estrito da atividade docente, sob pena de ser anulada a liberdade de consciência e de crença dos estudantes que formam, em sala de aula, uma audiência cativa." (CÂMARA DOS DEPUTADOS, 2019b). ${ }^{14}$ Ressalta, ademais, que os(as) docentes não têm "o direito de dizer aos filhos dos outros o que é certo e o que é errado em matéria de religião e de moral", com destaque para a moral sexual, ponto reforçado pelo PL n. 258/2019 (CÂMARA DOS DEPUTADOS, 2019c), do deputado Pastor Eurico (PATRI/PE), que desautoriza, no art. $3^{\circ}$, inciso XIV, parágrafo único, o desenvolvimento de políticas de ensino, currículo escolar e "disciplinas obrigatórias, nem mesmo de forma complementar ou facultativa, que tendam a aplicar a ideologia de gênero, o termo 'gênero' ou 'orientação sexual'."

$\mathrm{Na}$ contramão da confiança institucional requerida pelo pacto democrático, segundo o PL n. 246/2019 (CÂMARA DOS DEPUTADOS, 2019b), as escolas públicas (excetuandose as particulares de orientação confessional e ideologia específicas) são suspeitas de dogmatismo, proselitismo e sectarismo, e seus professores são acusados de uso de técnicas de manipulação psicológica para obter a adesão do alunado a determinada causa; de aproveitamento da audiência cativa do alunado para promover seus próprios interesses

14 Como é possivel exercer a liberdade de ensinar sem liberdade de expressão? Isso contraria a "valorização do profissional da educação escolar" estabelecida pela LDB (Art. $3^{\circ}$ VII) (BRASIL, 1996). Ademais, considerar estudantes vítimas potenciais de doutrinação política e ideológica significa concebê-los não "como sujeitos potencialmente livres, mas como desprovidos de senso crítico e capacidade de resistência, o que denota ignorância das teorias da aprendizagem." (CARVALH0, 2018, p. 64).. 
e preferências ideológicas, religiosas, morais, políticas e partidárias; de discriminação e constrangimento do alunado em razão de suas convicções políticas, ideológicas, morais ou religiosas, ou da falta delas; de propaganda político-partidária em sala de aula e incitação do alunado à participação em atos públicos (artigos $3^{\circ}$ e $4^{\circ}$ ). 0 argumento é que a suposta doutrinação política e ideológica em sala de aula cria as condições para o bullying político e ideológico que é praticado pelos próprios estudantes contra seus colegas.

Para garantir a "neutralidade docente", as instituições de educação básica deverão afixar cartazes com os "deveres do professor" nas salas de aula e salas dos professores (art. $5^{\circ}$ ); os(as) estudantes poderão gravar as aulas para "viabilizar o pleno exercício do direito dos pais ou responsáveis de ter ciência do processo pedagógico e avaliar a qualidade dos serviços prestados pela escola" (art. $7^{\circ}$ ); e o poder público disponibilizará canal de comunicação para receber denúncias anônimas a serem encaminhadas "ao órgão do Ministério Público incumbido da defesa dos direitos da criança e do adolescente" lart. 11) (CÂMARA DOS DEPUTADOS, 2019b). ${ }^{15}$ Surgiram iniciativas locais de "disque-denúncia" contra professores que se tornaram matéria do Supremo Tribunal Federal (STF). ${ }^{16}$ Em 3 de setembro de 2019, o ministro Edson Fachin "acatou um pedido do Ministério Público de Santa Catarina (MPSC) para cassar a decisão do Tribunal de Justiça de SC, que havia considerado o canal de denúncias legítimo", ratificando "entendimento do STF, que proibiu o cerceamento de manifestações no contexto estudantil" em todos os ambientes escolares. Segundo o ministro, o disque-denúncia estimula alunos(as) a se comportarem "como se agentes do Estado fossem, dando a entender que essa atuação é legítima, quando nem ao próprio Estado é conferido o poder de controlar tais manifestações." (SPAUTZ, 2019).

0 argumento, idêntico àquele constante no PL n. 193/2016 (BRASIL, 2016), de que a prática da doutrinação política e ideológica nas escolas seria antidemocrática ao "instrumentalizar o sistema público de ensino", visando "desequilibrar o jogo político em favor de determinados competidores", aponta a guerra cultural (HUNTER, 1991) entre humanistas seculares (defensores dos direitos humanos) e cristãos fundamentalistas (defensores da moral sexista e heterossexista), principalmente no tocante à educação para a sexualidade, igualdade e diversidade sexual e de gênero. Ora, os grupos que apoiam o Programa Escola sem Partido constituem precisamente um desses competidores, que tenta, via projeto de lei, desequilibrar o jogo político a seu favor, na contramão dos avanços dos direitos das

150 PL n. 246/2019 (CÂMARA DOS DEPUTADOS, 2019b) também estende essa vigilância legal às políticas e planos educacionais, aos conteúdos curriculares, aos projetos pedagógicos das escolas, aos materiais didáticos e paradidáticos, às avaliações para o ingresso no ensino superior, às provas de concurso para ingresso na carreira docente e até mesmo às instituições de ensino superior formadoras (art. $9^{\circ}$ ), além de proibir grêmios estudantis de promoverem atividade político-partidária (art. $\left.8^{\circ}\right)$.

16 A exemplo da iniciativa da deputada estadual catarinense Caroline Campagnolo do PSL. 0 Ministério Público de Santa Catarina (MPSC) solicitou à Suprema Corte cassação da decisão da desembargadora Maria Santa Rita, do Tribunal de Justiça de SC, que havia considerado o canal de denúncias legítimo (SPAUTZ, 2019). 
mulheres e das pessoas LGBTQl, que são frequentemente alvos de discriminação, bullying e outras violências na escola (CARVALHO, 2018).

Curiosamente, o discurso em prol dos princípios constitucionais da impessoalidade e do Estado laico está presente no PL n. 246/2019 (CÂMARA DOS DEPUTADOS, 2019b) ao censurar o uso do sistema estatal de ensino para defesa de interesses sectários, "incompatível com o princípio da neutralidade política e ideológica do Estado, com o princípio republicano, com o princípio da isonomia e com o princípio do pluralismo político e de ideias." (CÂMARA DOS DEPUTADOS, 2019b, p. 5). Adverte-se no documento que a neutralidade religiosa significa "não usar o sistema de ensino para promover valores que sejam hostis à moralidade dessa ou daquela religião", uma posição mais defensiva do fundamentalismo religioso dos grupos que apoiam o Programa Escola sem Partido do que das religiões hostilizadas na escola e na sociedade brasileira, que não são as cristãs.

Em suma, o Programa Escola sem Partido não é sobre os valores democráticos da tolerância e convivência na diversidade no cotidiano escolar, nem sobre a participação da família na escola nesse contexto, buscando consensos democráticos, mas sobre o controle de expressões "ideológicas, religiosas, morais, políticas e partidárias" antipatizadas por grupos de famílias que têm partido! Como afirmam Espinosa e Queiroz (2017, p. 61), é uma armadilha preconizar "que o Escola sem Partido possui natureza apartidária, e que não possui qualquer espécie de vinculação política, ideológica"; ao contrário, tem "forte vínculo com partidos ligados a segmentos evangélicos, como, por exemplo o PSC, cujo presidente é um pastor" e associase "ao que há de mais anacrônico na sociedade brasileira." Representa a ingerência de um grupo minoritário de famílias religiosas fundamentalistas que querem, elas sim, aparelhar a escola pública para ampliar a imposição de suas convicções políticas, ideológicas, morais e religiosas, no contexto da citada guerra cultural.

0 ideário democrático/igualitário da escola básica compulsória, pública/estatal, laica, com seu currículo comum, é possibilitar a superação das desigualdades sociais de origem pela educação. Essa promessa da escola moderna ${ }^{17}$ não eliminou as escolas privadas, inclusive confessionais, nem os investimentos familiares para gerar distinções vantajosas para sua prole (NOGUEIRA, 2010; MARTINS, 2019). Se, por um lado, na escola pública não seria viável os(as) alunos(as) receberem educação religiosa e moral idêntica às convicções particulares de seus pais, considerando-se a diversidade de famílias e religiões, por outro lado, não há conflito entre família e escola/currículo oficial, nem necessidade de afastar a criança do convívio escolar adotando-se o ensino em casa, quando pais/mães/responsáveis familiares são favoráveis ao pluralismo democrático e à convivência na diversidade, próprios 
da educação pública. Ademais, é fato que a maioria das famílias não está equipada ou preparada para assumir a educação formal em seu espaço e tempo, na vida familiar e no âmbito doméstico, nem com seus próprios recursos. ${ }^{18}$ Por outro lado, as escolas têm o importante papel de cuidado e vigilância do bem-estar das crianças, como lembram Brewer e Lubiensky (2017). Nesse contexto, é descabido o ataque à escola pública e a professores(as) pelos proponentes do "escola sem partido" em nome de "valores tradicionais", ou seja, de vieses classistas, racistas, sexistas e heterossexistas, como apontam Freitas e Baldan (2017).

0 PL n. 3.261/2015 (CÂMARA DOS DEPUTADOS, 2015), do deputado Eduardo Bolsonaro, argumentava que

a simples convivência em ambiente escolar multisseriado, com a presença de crianças e adolescentes de variadas idades, por si só, enseja preocupação e inquietude em questões relacionadas a violência, drogas, sexualidade precoce, bullying, valores culturais e religiosos etc. (CÂMARA DOS DEPUTADOS, 2015, p. 8).

Embora reconhecesse "a falta de socialização com outras crianças" como um ponto desfavorável, contrapunha que "não pode ser imposta pelo Estado em ambiente diverso ao desejado por quem detém o pátrio poder" e que as famílias podem "fornecer ensino domiciliar e a convivência social em círculos eleitos por cada uma delas." (CÂMARA DOS DEPUTADOS, 2015, p. 8). Para isso, propunha inserir a opção pelo ensino domiciliar na LDB, autorizando-o em todos os níveis da educação básica (Art. 21), com exigência de matrícula e frequência a exames para fins de avaliação e certificação de conclusão de séries e níveis escolares, cabendo aos aluno, previamente matriculados nesse regime o cumprimento do calendário de avaliações, e à instituição de ensino expedir históricos escolares, declarações de conclusão de série e diplomas ou certificados de conclusão de cursos (Art. 24).

Mais detalhado que o PL n. 3.261/2015 (CÂMARA DOS DEPUTADOS, 2015) no sentido da regulamentação, o PL n. 2401/2019 (CÂMARA DOS DEPUTADOS, 2019d) dispõe sobre o exercício do direito à educação domiciliar no âmbito da educação básica, alterando o ECA e a LDB. № Art. $1^{\circ}$ define a educação domiciliar como o "regime de ensino de crianças e adolescentes, dirigido pelos próprios pais ou pelos responsáveis legais, [visando] ao pleno desenvolvimento da pessoa, seu preparo para o exercício da cidadania e sua qualificação para o trabalho", assim como a educação escolar! (CÂMARA DOS DEPUTADOS, 2019d). Nas palavras de Rick Dias,

18 0 retorno da educação em casa é um anacronismo. Historicamente, a escola para todos superou a educação em casa, restrita às famílias letradas e abastadas do passado, que podiam contratar professores particulares, já que não era o pai ou a mãe que ensinava as primeiras letras, as artes e ofícios, muito menos os conhecimentos superiores. A escolarização básica é uma invenção social recente e, "de uma perspectiva histórica, é por causa dos limites educativos das famílias que temos escolas." (CARVALH0, 2018, p. 62). 
presidente da ANED, "ensino domiciliar são os pais se responsabilizando por todo o processo educacional, inclusive a parte acadêmica que antes estava a cargo da escola." (CÂMARA DOS DEPUTADOS, 2019a).

No Art. $2^{\circ}$ estabelece que "os pais ou os responsáveis legais têm prioridade de direito na escolha do tipo de instrução que será ministrada a seus filhos", entre a educação escolar e a educação domiciliar, devendo os que optarem pela educação domiciliar "assegurar a convivência familiar e comunitária." No Art. $3^{\circ}$ assegura "a isonomia de direitos entre os estudantes em educação escolar e os estudantes em educação domiciliar." No Art. $4^{\circ}$ detalha a documentação ${ }^{19}$ - destacando-se o plano pedagógico individual anual - a ser inserida pelos pais ou responsáveis legais do estudante, na plataforma virtual do MEC que, após análise e aprovação, gerará comprovante de matrícula em educação domiciliar, a ser renovada anualmente (CÂMARA DOS DEPUTADOS, 2019d).

Assim, os pais ou responsáveis legais deverão manter registro periódico das atividades pedagógicas do estudante, como parte da supervisão da educação domiciliar, conforme ○ Art. $5^{\circ} .0$ Art. $6^{\circ}$ determina a submissão do estudante a uma avaliação anual para certificação da aprendizagem a partir do $2^{\circ}$ ano do ensino fundamental, preferencialmente no mês de outubro, sob a gestão do MEC, baseada nos conteúdos do ano escolar correspondente à idade do estudante, de acordo com a Base Nacional Comum Curricular. 0 Art. $7^{\circ}$ prevê reaplicação por ausência justificada e prova de recuperação, devendo o MEC divulgar o calendário das avaliações (Art. $8^{\circ}$ ) e cobrar taxa de custeio (Art. 9) (CÂMARA DOS DEPUTADOS, 2019d).

0 Art. 10 do PL n. 2.401/2019 (CÂMARA DOS DEPUTADOS, 2019d) estipula que caberá aos pais ou responsáveis legais monitorar de forma permanente $\mathrm{o}$ desenvolvimento e a aprendizagem do estudante em educação domiciliar, conforme as diretrizes curriculares nacionais, sendo facultado a instituições públicas e privadas oferecerem avaliações formativas ao longo do ano letivo (Art. 11.). Contudo, segundo o Art. १३, os pais ou responsáveis legais perderão o exercício do direito à educação domiciliar em caso de reprovação lem dois anos consecutivos, ou em três anos não consecutivos) nas avaliações anuais e provas de recuperação, ou quando injustificadamente o estudante não comparecer à avaliação anual.

0 Art. 16 prevê que as despesas decorrentes do disposto na Lei correrão à conta de dotação orçamentária consignada anualmente ao MEC. E há despesas com a regulação da educação domiciliar, não somente com a criação e manutenção da plataforma virtual, mas com a supervisão e as avaliações anuais centralizadas no MEC. Diferentemente do PL $n$. 3.261/2015 (CÂMARA DOS DEPUTAD0S, 2015), que indicava matrícula escolar, frequência a exames

19 Identificação do estudante, comprovante de residência, termo de responsabilização pela opção de educação domiciliar assinado pelos pais ou responsáveis legais, certidões criminais (ver Art. १2), caderneta de vacinação atualizada, além do plano pedagógico individual. 
e expedição de certificações por escola pública ou privada local, o PL n. 2.401/2019 (CÂMARA DOS DEPUTADOS, 2019d) supõe a criação de uma estrutura própria para atender estudantes em educação domiciliar em todo o País, praticamente um novo sistema no MEC! Contudo, sua justificativa aponta interesse "econômico, tendo em conta que [...] o reconhecimento do homeshooling poderia reduzir os gastos públicos com a educação."20 (CÂMARA DOS DEPUTADOS, 2019d).

Segundo Andrade (2017, p. 175), a regulação estatal da educação domiciliar em diferentes países oscila entre abordagens minimalistas, calcadas na afirmação das liberdades individuais fundamentais e do poder familiar, e maximalistas, motivadas "por preocupações com o bem-estar infantil, a igualdade de gênero, ou a doutrinação ideológica." Isso porque a educação é direito da criança e pode haver negligência parental, sem falar de abuso; ${ }^{21}$ porque a criação e o acompanhamento da educação infantil têm ficado tradicionalmente a cargo das mulheres; ${ }^{22}$ e porque o interesse na educação domiciliar tem sido de famílias fundamentalistas religiosas reacionárias, contrárias ao acesso dos(as) filhos(as) ao conhecimento científico e às diversas expressões culturais contemporâneas. Em todo caso, segundo o autor, há normas sobre a obrigatoriedade da matrícula escolar (ou não, como no PL n. 2.401/2019), sobre "as especificidades do controle e da avaliação dos resultados do ensino-aprendizagem" e sobre "a qualificação do pai/mãe/responsável legal que pretenda promover a educação domiciliar da criança ou do adolescente", inclusive com "testes de competência para os pais educadores e avaliação curricular, além de testes anuais aplicados à criança ou ao adolescente." (ANDRADE, 2017, p. 173, 175).

A reportagem que anunciava o envio do PL n. 2.401/2019 (CÂMARA DOS DEPUTADOS, 2019d) à Câmara Federal ressalvava que, "para evitar abusos" por parte da família, não seria autorizada a educação domiciliar

no caso de pais condenados por crimes previstos no ECA (Lei n. 8.069/90), na Lei Maria da Penha (Lei n. 11.340/06), no capitulo de crimes contra a dignidade sexual do Código Penal (Decreto-Lei n. 2.848/40), na Lei Antidrogas (Lei n. 11.343/06) e na Lei dos Crimes Hediondos (Lei n. 8.072/90). (CÂMARA DOS DEPUTADOS, 2019d).

20 Brewer e Lubiensky (2017) contestam esse argumento.

21 Ver The Coalition for Responsible Home Education (CRHE), organização estadunidense sem fins lucrativos, declaradamente sem afiliação religiosa ou política, fundada por egressos da educação domiciliar para advogar pelos interesses de crianças educadas em casa. Sua missão é "empoderar crianças educadas em casa, educando o público e advogando por políticas e práticas centradas na criança e baseadas em evidências para famílias e profissionais." (COALITION FOR RESPONSIBLE HOME EDUCATION, [201-]).

22 No Canadá a educação domiciliar é chamada de "mom schools" (BOSETTl; VAN PELT, 2017, p. 42). 


\section{ENTRE RETÓRICA E REALIDADE: REAÇÕES DE INTERNAUTAS À EDUCAÇÃO DOMICILIAR}

A reportagem sobre o lançamento do PL n. 2.401/2019 (CÂMARA DOS DEPUTADOS, 2019d), aqui analisada, pontuava algumas críticas à educação domiciliar: a socialização restrita e o não acesso a outras formas de ver o mundo além da família; e a proteção contra a própria família disfuncional, já que as violências praticadas dentro de casa contra as crianças geralmente são identificadas na escola. Citava Cesar Callegari, membro do Conselho Nacional de Educação (CNE) e ex-secretário de Educação Básica do MEC, que advertia ser a educação domiciliar prejudicial à formação integral das crianças e jovens e apostava na sua rejeição pelo Congresso (OLIVEIRA, 2019). Seguiam-se 649 comentários de internautas, ${ }^{23}$ a grande maioria do sexo masculino, selecionados aqui segundo a pertinência temática com referência a duas amplas categorias: "relações família-escola" e "profissionalidade docente". São comentados a seguir, visando ilustrar a complexidade da educação domiciliar e suas implicações para a profissionalidade docente.

Não é possivel saber a profissão dos internautas que discutiram a reportagem, mas pelo conteúdo do debate é plausível supor que muitos sejam professores e professoras. Alguns viram na educação domiciliar um novo nicho de trabalho docente, diante dos limites pedagógicos das famílias:

\footnotetext{
Esse projeto vai ser ótimo para professores ganharem um extra sobre aqueles poucos que podem e querem fazer o HS [homeschoolingl. Se o aluno chumbar, vai voltar pra sala de aula, isso vai aumentar muito a procura pelo ensino particular [aulas particulares].

Mais oferta de trabalho para os professores! Estou gostando da ideia, pois sou professor e imagino que seja melhor ensinar em domicílio do que enfrentar uma sala cheia. (informações verbais).
}

Outros reconheceram que a grande maioria das famílias simplesmente não poderia arcar com os custos, de forma que a educação domiciliar seria opção de poucas e não ameaçaria a educação escolar. Por outro lado, poderia sinalizar uma política de retirada do investimento público no sistema escolar, com desemprego dos professores:

23 Houve críticas e contestações à redução do estado e suas consequências para a escola pública, a segurança, a saúde e a seguridade social; defesa do discurso neoliberal; discursos de teor religioso, antiesquerdista e partidário em torno do reconhecimento da importância da escola; menções a "petralhas" versus "bozopatas" e a figuras políticas diversas (OLIVEIRA, 2019). 
Caríssimo. Inviável para pobre. 0 governo vai financiar tudo por via de dedução no Imposto de Renda. Vai faltar dinheiro para as escolas tradicionais?

É fato que não serão muitas famílias que conseguirão fazer o homeschooling, pois para fazer o projeto pedagógico e para manter uma qualidade para passar de ano sem reprovar vai ter que desembolsar uma grana. Bom para os professores ganharem um extra, bom para as familias que podem pagar.

Parabéns... Se todos optarem por educar em casa, pobres professores... Vão vender quentinhas para sobreviver. Se não bastassem os $15 \%$ de desempregados... (informações verbais).

Também questionaram explicitamente a formação e competência dos pais lem pedagogia, nas várias matérias curriculares) para assumirem a educação domiciliar. A possibilidade de atuação pedagógica de um pai/mãe educador-leigo de seu filho(a) em casa se contrapõe à profissionalidade docente, que requer domínio didático e curricular. Talvez a histórica desprofissionalização do magistério (que ainda lutamos para efetivamente superar) e a família educadora de outrora (conquanto rarefeita) existam no imaginário dos proponentes da educação domiciliar. Porém, os internautas fizeram críticas incisivas à possibilidade de uma educação, nos moldes do currículo escolar multidisciplinar, ministrada por pais leigos no lugar do(a) professor(a) com formação especializada/pedagógica:

Qual o nivel de escolaridade que os pais devem ter para educar os filhos em casa?

Veremos pais engenheiros, advogados, arquitetos, médicos, bibliotecários, fisioterapeutas... fazendo PROJETOS PEDAGÓGICOS sem nem terem ideia de como é isso kkk. Vai dar "certo" sim... pode confiar.

Isso pode ser possivel se o pai ou a mãe tiver curso de pedagogia completo, e parem de diminuir a importância dos professores, eles estudam para ensinar... (informações verbais).

Por um lado, como argumentaram alguns internautas, que famílias adeptas da educação domiciliar dominariam todo o currículo seriado para poderem dispensar a contratação de professores particulares em domicilio? E, por outro lado, que famílias poderiam pagar esses serviços exclusivos?

Até que idade isso é permitido? Se forem os pais mesmo a ensinarem, - quanto eles sabem para realmente poder ensinar? Em uma escola se têm vários professores de áreas diferentes para ensinar, então como uma pessoa pode ter a arrogância de achar que pode ensinar de tudo? Quanto a professores particulares, nesse caso só sendo bem rico. 
Essa lei não foi feita para a maioria. É só para $1 \%$ da população que realmente tem bagagem suficiente para educar os próprios filhos, ou então com $\$ \$ \$$ suficiente para contratar um educador. (informações verbais).

Havendo crescimento da educação domiciliar, Andrade (2017, p. 190) imagina um cenário em que, a par da "significativa redução de custos orçamentários públicos com a manutenção do sistema escolar ante a diminuição do número de alunos que frequentam regularmente a escola", os sistemas de ensino poderiam prover apoio pedagógico, capacitação e aperfeiçoamento para pais-educadores e apoiar entidades associativas de pais e educadores. Contudo, alguns internautas reafirmaram a necessidade da escola até como referência para a educação domiciliar, bem como a serventia dos educadores profissionais para liberar os pais/mães:

\begin{abstract}
Alô pais! Muito simples o projeto pedagógico: retire os dados da LDB ou pegue o de uma boa escola como referêncial! Boa sorte!!

Quero ver se vocês (pais) terão bagagem, "conhecimento o suficiente" e muita, mas bota muita paciência nisso, para ensinar os seus filhos em casa. Ruim na escola, pior sem ela. (informações verbais).
\end{abstract}

Houve, ainda, quem ironizasse a pretensão da educação domiciliar superar a educação escolar, aludindo à trabalheira que é ensinar e à desvalorização do trabalho docente: "Na escola não vai bem, imagine em casa, isso não dá certo." "Bom que poderemos ensinar nossos filhos com qualidade já que esses professores(as) são um bando de PREGUIÇOSOS." (informações verbais).

Internautas mencionaram, também, a complementação ou mesmo a viabilização da educação domiciliar com soluções tecnológicas baratas que substituiriam com vantagem os próprios pais-educadores e superariam a qualidade do ensino e ambiente escolar:

Cara, com esse método terão cursinhos on-line, com preços bem acessíveis, os pais deverão fiscalizar os simulados semanais.

Contratarei um curso on-line de alto nível que vai estar na média de 500 reais anuais e só fiscalizarei os simulados semanais.

Qualquer ensino on-line hoje é muito melhor que qualquer aula na escola. Os cursos on-line melhoraram muito. 0 aluno pode voltar e repetir a aula quantas vezes quiser. Hoje a maioria das escolas só ensina o que não presta, fora a violência e drogas. (informações verbais). 
Enfim, a complexidade das relações família-escola mediadas pelo Estado e pela política educacional é ilustrada pelas altercações entre internautas que apontam para a disputa entre concepções opostas, atravessadas por adesões político-partidárias: uma, coletivista, referente ao dever do estado; outra, individualista, atinente ao direito de escolha, de fato reservado a poucas famílias.

[..] como que os pais que trabalham o dia inteiro terão tempo para desenvolver plano pedagógico sem formação técnica e aplicar aulas para a criança/adolescente? Projeto sem pé nem cabeça. Por que não tomam medidas que melhoram a estrutura das escolas, valorizem os professores, que ofereçam aula em período integral, escolas técnicas e ensino superior?

0 projeto vem regulamentar uma prática que já existe. Pais que trabalham o dia inteiro e que não têm formação para fazer projeto pedagógico não conseguirão nem se inscrever no HS, e serão proibidos de assim fazer caso seu filho reprove nas avaliaç̃̃es. Esse projeto é bom para os professores ganharem um extra e para as familias que podem, não vai ter impacto nas contas públicas ou no ensino em geral.

[...] Formação é um papel do Estado e não da Família. Daqui a pouco vem outro projeto que a família pode aplicar remédio para seu parente, se ele fica doente. Um governo que foge à responsabilidade de dar a Educação para suas crianças e jovens...

Isolar os filhos do mundo... tentar colocá-los numa redoma de vidro é a maior burrice... temos que prepará-los para a vida... privar uma criança do contato social é nocivo e perturbador...

[...] PERGUNTO: Quem o está privando de fazer isso, "preparar seus filhos para a vida", etc. ATRAVÉS DE ESCOLA TRADICIONAL DO ESTADO? Essa lei não o obriga e a nenhum outro a RETIRÁ-LOS da "amada" escola para ensinar e educar em casa, mas apenas estabelece a PERMISSÃO (que antes não havia) se assim o queira, desde que cumpridos os requisitos estabelecidos. Essa é APENAS mais uma OPÇÃO, entenda "OPÇÃO" para quem se acha capacitado fazê-lo em família e não IMPOSIÇÃO.

Em tempo: "Por que para ensinar e educar seus filhos tem que ser OBRIGATORIAMENTE feito pelo Estado, numa escola bancada por esse Estado? Por que não mais 1 ou 2 opções não obrigatórias ao modelo? As escolas particulares já são uma dessas opções, vindo agora a ESCOLA FAMLLAR a somar-se como opção. (informações verbais).

De acordo com Andrade (2017, p. 186), o debate sobre "a liberdade de escolha da prática de educação domiciliar, bem como a determinação de limites, modos e agentes de controle estatais" passa pela "tríade Família ou Estado ou Criança/Adolescente", ou seja, contrapõe opção dos pais (direito de liberdade individual), interesse público e direitos sociais (interesse estrito da criança). Apenas duas internautas mulheres referiram-se à proteção da criança contra a violência familiar, detectada pela escola: "Num país onde a maioria dos casos 
de agressão física e psicológica acontecem dentro de casa, esse projeto é uma temeridade." “Aonde e para quem a criança vai dar sinais disso agora!̣" (informações verbais).

Antecipando essas questões, o PL n. 2.401/2019 (CÂMARA DOS DEPUTADOS, 2019d) dispõe que os pais deverão garantir a convivência social dos filhos e que pais condenados por crimes previstos no ECA, na Lei Maria da Penha e na Lei de Crimes Hediondos estão proibidos de pleitear o ensino domiciliar, como já referido.

\section{AMEAÇAS À EDUCAÇÃO PÚBLICA E À PROFISSIONALIDADE DOCENTE}

Ao discorrer sobre os contextos, conceitos e discursos envolvidos no debate dos projetos "escola sem partido" e "educação domiciliar", situados e articulados no contexto ideológico neoliberal e neoconservador que vivemos, corroboram-se as análises que vêm denunciando seu ataque à educação pública e à profissionalidade docente. ${ }^{24}$ De um lado, temse a tentativa de controle e censura do currículo escolar e da prática docente por famílias que invocam seu suposto direito a que seus filhos recebam educação conforme a convicção e moral familiar na escola pública, privatizando-a e subordinando os(as) professores(as) aos pais. De outro lado, alternativamente, tem-se a retirada das crianças do espaço público da escola para receberem toda educação em casa, sob escrutínio dos pais, eliminando-se o(a) profissional da educação, ou contratando-ola) e supervisionando-o(a) diretamente.

As questões embutidas nos dois projetos referem-se à confusão entre educação pública e privada/doméstica e entre as funções educativas da escola e da família, instituições com finalidades distintas e contextos e limites específicos. As famílias contemporâneas "são pequenas organizações encarregadas da reprodução biológica e social, dependentes de outras instituições para a sobrevivência cotidiana", entre as quais a escola, para a guarda e educação das crianças e jovens. "Já as escolas são organizações encarregadas da reprodução cultural/social, que contam com um corpo de profissionais especializados, integram um sistema/rede e implementam uma política/currículo oficial" (CARVALH0, 2018, p. 61) para todos(as) os(as) alunos(as), independentemente e além de suas culturas familiares.

Entre os aspectos problemáticos dessas questões estão a imposição de limites éticos e jurídicos à atividade docente, acusada de doutrinação político-partidária, ideológica e moral, com estímulo a denúncias contra professores(as) (no caso do Programa Escola

24 Sobre Escola sem Partido ver coletânea organizada por Frigotto (2017) e dossiê organizado por Freitas e Baldan (2017) na Revista Fênix - Revista de História e Estudos Culturais. Sobre Educação Domiciliar ver dossiê: Homeschooling e o direito à educação, organizado por Oliveira e Barbosa (2017) na Revista Pro-posições. 
sem Partido), e a falsa defesa dos interesses da criança e do adolescente, na contramão da convivência na diversidade própria da esfera pública e da construção da cidadania na escola (no caso dos dois projetos). Em ambos, o pressuposto é que a família tem competência, tempo e disposição para avaliar, ministrar e quiçá determinar o currículo escolar, ignorando-se a natureza da política educacional e a profissionalidade docente.

Se o desejo de controle da educação dos(as) filhos(as), expresso no slogan "meus filhos minhas regras", não é viável além do microcosmo familiar, o projeto de "educação domiciliar" possibilita à família controle direto do currículo e atuação em lugar do(a) docente ou colocando-o(a) a seu exclusivo serviço. Ademais, a ilusão da família educadora, autônoma e capaz de controlar as aprendizagens dos(as) filhos(as) só se sustentaria para pais/mães dotados de tempo, preparo pedagógico e gosto pelas matérias escolares, ou de recursos financeiros para prover professores(as) particulares estritamente selecionados por afinidade ideológica, e ademais contando com filhos(as) submissos(as), numa situação de reprodução social total. Como argumentaram os internautas, não seria fácil para a grande maioria das famílias dispensar a escola e os(as) professores.

Segundo a Associação Nacional de Educação Domiciliar (ANED), 7.500 famílias praticavam a educação domiciliar em 2019 no Brasil, para 15.000 estudantes entre quatro e 17 anos, ${ }^{25}$ sendo a razão família/filhos de um para dois. Contudo, ainda não se têm pesquisas empíricas sobre a avaliação da escola pública e do currículo escolar pelos pais/mães nem sobre tendências à educação domiciliar. Uma exceção é a pesquisa pioneira de Vieira (2012), abrangendo 12 estados das diversas regiões brasileiras, com concentração em Minas Gerais. Entre os 62 pais/mães de sua amostra, o autor encontrou um número significativo que reivindica "o direito e a responsabilidade de educar os filhos" para lhes "dar uma formação integral" (VIEIRA, 2012, p. 52). As motivações declaradas são religiosas ${ }^{26}$ e morais ou "ambientais", ou seja, os pais consideram "o ambiente de socialização escolar nocivo". Há também "motivações pedagógicas e as alegações de que o ensino regular ou o ambiente de aprendizado convencional é pobre e ineficaz (não necessariamente segundo parâmetros religiosos e morais)" (VIEIRA, 2012, p. 52). Destaca-se a idade média dos estudantes educados em casa: 7,8 anos, correspondente às séries iniciais do ensino fundamental (VIEIRA, 2012, p. 54).

As conclusões de Vieira (2012, p. 8) são de que os pais-educadores brasileiros "apresentam um perfil socioeconômico e ideológico bastante próximo dos adeptos de outros países, especificamente dos norte-americanos" e não correspondem a críticas de que "seriam individualistas, intolerantes ou isolacionistas." São de classe média e têm elevado capital

25 Consulta feita no site da ANED em 10/10/2019. Ver https://www.aned.org.br/.

26 Vieira (2012, p. 26) destaca "o trânsito de ideias entre as comunidades protestantes americana e brasileira lexemplificado] nas experiências de muitas famílias que adotaram a educação domiciliar por influência de líderes religiosos brasileiros (pastores) inspirados em líderes daquele país." 
cultural, evidenciado pelo grau de escolaridade da maioria, estando as mães à frente do processo de educação domiciliar, que custa financeiramente pouco em comparação com o custo de uma escola privada (VIEIRA, 2012, p. 53). ${ }^{27}$

Se, por um lado, o movimento de educação domiciliar se insere no contexto da ideologia neoliberal, que o legitima a partir da lógica da liberdade de escolha (OLIVEIRA; BARBOSA, 2017), constituindo "a forma mais extrema de descentralização e privatização na educação" (BREWER; LUBIENSKY, 2017, p. 33), por outro lado, Aurini e Davies (2005) destacam que tal escolha não seria possível se não contasse, como ocorre atualmente, com condições logísticas que facilitam o ensino fora do aparelho escolar e possibilitam atender necessidades customizadas: difusão do acesso à internet, computadores, materiais didáticos e métodos pedagógicos diversificados, redes de apoio, inclusive organizações emergentes de homeschoolers, e, como nunca houve na história, grande número de pais - especialmente mães - com escolaridade superior (AURIN; DAVIESM, 2005, p. 467).

Enfim, o traço distintivo da educação domiciliar, segundo Aurini e Davies (2005), é sua lógica 'expressiva': em vez de buscar vantagens instrumentais, a cultura da parentalidade intensiva focaliza o desenvolvimento e as necessidades únicas da criança, ao removê-la do mercado (e da burocracia) escolar para oferecer-lhe atenção pessoal, uma pedagogia alternativa e customizada e um currículo e ambiente de aprendizagem individualizados, aspectos também destacados por Ray (2015). Trata-se de uma cultura das classes médias, que requer um adulto fora do mercado de trabalho disponível para a tarefa de educar uma ou mais crianças em casa (geralmente a mãe), o que demanda sacrifícios financeiros e de carreira, além de formação pedagógica para criar um currículo especializado, dentre as várias alternativas pedagógicas disponíveis. Se, por um lado, a educação domiciliar é economicamente ineficiente, pois os pais/mães abandonam empregos bem pagos para se lançarem num projeto arriscado e incerto, por outro lado, veem nessa opção benefícios culturais como: inculcação de valores parentais (religiosos ou contraculturais), fortalecimento da unidade familiar e/ou proteção contra o álcool e as drogas, violências, racismo, bullying, pressão dos pares, consumismo e iniciação sexual no ambiente escolar, pontos igualmente realçados por Ray (2015).

Contudo, pais/mães com elevada escolaridade podem substituir a(o) profissional da educação no ensino do currículo escolar? Lembre-se que a profissionalidade docente,

27 Ver Bosetti e Van Pelt (2017), Aurini e Davies (2005) e Ray (2015) sobre homeschooling no Canadá e Estados Unidos. The Coalition for Responsible Home Education (CRHE) ([201-], tradução nossa) resume assim a motivação dos pais/mães: "um número crescente e diverso de famílias tem aderido ao homeschooling, nem tanto por razões pedagógicas ou religiosas, mas por razões individuais pragmáticas, incluindo preocupações com o bullying ou com a precária qualidade escolar." Já Brewer e Lubiensky (2017) afirmam que o arrazoado religioso é a principal justificativa ideológica para a educação domiciliar nos Estados Unidos, embora preocupações com violência racial (no caso de famílias afro-americanas) e segurança também tenham influência. 
fundada em conhecimentos e competências especializados latestados por titulação e desenvolvidos na atuação profissional) e numa identidade profissional estabelecida, contrapõe-se historicamente à figura do(a) professor(a) leigo(a), ainda recente entre nós. Mas não se trata apenas de qualificação, mas também de disposição. A atuação de pais e mães como educadores(as) dos(as) filhos(as) se sustentaria ao longo dos anos de formação de crianças e jovens e por todas as matérias escolares? Diante de tamanho desafio, cabe ponderar que se a educação domiciliar dispensa a escola, pode não dispensar necessariamente o(a) profissional docente, como observaram os internautas. Sua clivagem de classe, apontada por Vieira (2012), confirma a observação de Vasconcelos (2017, p. 131) de que "os pretensos adeptos da homeschooling no Brasil, provavelmente, não seriam oriundos da escola pública, mas, sim, da escola privada." Nesse âmbito, já se pode antever que, se os empresários da educação perderem clientes, poderão ganhar com a oferta de serviços educativos diversificados, tanto para os(as) estudantes quanto para seus pais/mães, inclusive no formato EaD, como apontaram os internautas. Não sendo novidade a oferta de aulas particulares, acompanhamento ou reforço escolar, bem como de cursos extracurriculares (artes, línguas, esportes), voltados ao desenvolvimento pessoal ou ao acúmulo de outras formas de capital cultural além do escolar, esse mercado ${ }^{28}$ poderia crescer para englobar as atividades propriamente curriculares em novos formatos, apoiando os pais no planejamento didático e na avaliação formativa. Isso teria implicações para a profissão docente, ampliando seu leque de qualificações, competências e modos de atuação.

Assim, pode-se concluir destacando algumas contradições contidas nos discursos dos projetos "escola sem partido "e "educação domiciliar". Ao atacar a escola pública, negando a liberdade de ensinar e aprender, o Programa Escola sem Partido afirma sua importância como espaço de "guerra cultural" por visões de mundo e de formação humana, bem como a importância do(a) professor(a). Já a educação domiciliar, abraçada por uma ínfima parte da população, nega a escola, mas pode chamar de volta o(a) professor(a) à casa, ampliando e diversificando o mercado de serviços educativos e as oportunidades para o exercício profissional docente, o que poderia impulsionar a regulamentação da profissão.

\section{REFERÊNCIAS}

ANDRADE, É. P. de. Educação Domiciliar: encontrando o Direito. Pro-posições, v. 28, n. 2, p. 172-192, maio/ago. 2017.

ASSOCIAÇÃO NACIONAL DE EDUCAÇÃO DOMICILIAR. Breve Histórico. [S. l.: s. n.], 2019. Disponível em: https:// www.aned.org.br/sobre-nos/breve-historico-da-aned. Acesso em: 19 ago. 2019.

28 Sobre o crescimento da oferta desses serviços no Brasil ver Carvalho (2013) e Martins (2019). 
AURINI, J.; DAVIES, S. Choice without markets: homeschooling in the context of private education. British Journal of Sociology of Education, v. 26, n. 4, p. 461-474, Sept. 2005.

BOURDIEU, P.; PASSERON, J.-C. A reprodução: elementos para uma teoria do sistema de ensino. Rio de Janeiro: Francisco Alves, 1975.

BOSETTI, L.; VAN PELT, D. Provisions for homeschooling in Canada: parental rights and the role of the state. Pro-posições, v. 28, n. 2, p. 39-56, maio/ago. 2017.

BRASIL. Lei n. 9.394, de 20 de dezembro de 1996. Estabelece as diretrizes e bases da Educação Nacional. Senado Federal. Diário Oficial da União, Brasília, DF, 21 dez. 1996. Disponível em: http://www. planalto.gov.br/ccivil_03/leis/19394.htm. Acesso em: 19 ago. 2019.

BRASIL. Senado Federal. Projeto de Lei 193/2016. Inclui entre as diretrizes e bases da educação nacional, de que trata a Lei $n^{\circ}$ 9.394, de 20 de dezembro de 1996, o "Programa Escola sem Partido". Brasilia, DF, 3 maio 2016. Disponivel em: https://www25.senado.leg.br/web/atividade/materias/-/materia/१२5666. Acesso em: 19 ago. 2019.

BREWER, T. J.; LUBIENSKY, C. Homeschooling in the United States: examining the Rationales for Individualizing Education. Pro-posições, v. 28, n. 2, p. 21-38, maio/ago. 2017.

CÂMARA DOS DEPUTADOS. Projeto cria regras para educação domiciliar no Brasil. Agência Câmara de Notícias, Brasilia, DF, 7 maio 2019a. Disponível em: https://www.camara.leg.br/noticias/556888-PR0JETO-CRIA-REGRAS-PARA-EDUCACAO-DOMICILIAR-NO-BRASIL. Acesso em: 19 ago. 2019.

CÂMARA DOS DEPUTADOS. Projeto de Lei 246/2019. Institui o "Programa Escola sem Partido". Brasília, DF, 4 fev. 2019b. Disponível em: https://www.camara.leg.br/proposicoesWeb/fichadetramitacao?idProposic ao=2190752. Acesso em: 19 ago. 2019.

CÂMARA DOS DEPUTADOS. Projeto de Lei n. 258/2019. Dispõe sobre o direito dos alunos de aprender sem ideologia político-partidária. Brasilia, DF, 4 fev. 2019c. Disponível em: https://www.camara.leg.br/ proposicoesWeb/fichadetramitacao?idProposicao=2190772. Acesso em: 19 ago. 2019.

CÂMARA DOS DEPUTADOS. Projeto de Lei n. 2.401/2019. Dispõe sobre o exercício do direito à educação domiciliar, altera a Lei $n^{\circ} 8.069$, de 13 de julho de 1990 - Estatuto da Criança e do Adolescente, e a Lei $n^{\circ}$ 9.394, de 20 de dezembro de 1996, que estabelece as diretrizes e bases da educação nacional. Brasilia, DF, 14 abr. 2019d. Disponivel em: https://www.camara.leg.br/proposicoesWeb/fichadetramitaca o?idProposicao=2198615. Acesso em: 19 ago. 2019.

CÂMARA DOS DEPUTADOS. Projeto de Lei n. 3.261/2015. Autoriza o ensino domiciliar na educação básica, formada pela educação infantil, ensino fundamental e ensino médio para os menores de 18 (dezoito) anos, altera dispositivos da Lei $n^{\circ}$ 9.394, de 20 de dezembro de 1996, que estabelece as diretrizes e bases da educação nacional, e da Lei $n^{\circ} 8.069$, de 13 de julho de 1990, que dispõe sobre o Estatuto da Criança e do Adolescente e dá outras providências. Brasília, DF, 8 out. 2015. Disponível em: 
https://www.camara.leg.br/proposicoesWeb/fichadetramitacao?idProposicao=2017117. Acesso em: 19 ago. 2019.

CÂMARA DOS DEPUTADOS. Projeto de Lei n. 7.180/2014. Inclui entre os princípios do ensino o respeito às convicções do aluno, de seus pais ou responsáveis, dando precedência aos valores de ordem familiar sobre a educação escolar nos aspectos relacionados à educação moral, sexual e religiosa. Brasilia, DF, 24 fev. 2014. Disponivel em: https://www.camara.leg.br/proposicoesWeb/fichadetramitaca o?̣idProposicao=606722. Acesso em: 19 ago. 2019.

CÂMARA DOS DEPUTADOS. Projeto de Lei n. 10.185/2018. Altera a Lei n 9.394, de 1996, de diretrizes e bases da educação nacional, e a Lei n 8.069 , de 1990, o Estatuto da Criança e do Adolescente, para dispor sobre a possibilidade de oferta domiciliar da educação básica. Brasília, DF, 9 maio 2018a. Disponivel em: https://www.camara.leg.br/proposicoesWeb/fichadetramitacao?idProposicao=2174364. Acesso em: 19 ago. 2019.

CÂMARA DOS DEPUTADOS. Sem consenso, projeto sobre Escola sem Partido será arquivado. Agência Câmara de Notícias, Brasilia, DF, 11 dez. 2018b. Disponivel em: https://www.camara.leg.br/ noticias/549616-sem-consenso-projeto-sobre-escola-sem-partido-sera-arquivado/. Acesso em: 19 ago. 2019.

CARVALHO, M. E. P. de. Diversidade $x$ totalitarismo na escola: crítica ao projeto "escola sem partido. In: MONTEIRO, S. B.; OLINI, P. (org.). Currículo e docência. Cuiabá: EdUFMT; Editora Sustentável, 2018. v. 2. p. 54-69. (Coleção Endipe).

CARVALHO, M. E. P. de. Entre a escola e a família: a instituição informal do reforço escolar. In: ROMANELLI, G.. NOGUEIRA, M. A.I ZAGO, N. (org.). Família e escola: novas perspectivas de análise. 1. ed. Petrópolis: Vozes, 2013. p. 220-253.

CARVALHO, M. E. P. de. Escola como extensão da família ou família como extensão da escola? 0 dever de casa e as relações familia-escola. Revista Brasileira de Educação, n. 25, p. 94-104, jan./abr. 2004a.

CARVALHO, M. E. P. de. Modos de educação, gênero e relações escola-família. Cadernos de Pesquisa, v. 34, n. १२1, p. 41-58, jan./abr. 2004b.

COALITION FOR RESPONSIBLE HOME EDUCATION. A Brief History of Homeschooling. [S. l.: CRHE, [201-]. Disponivel em: https://responsiblehomeschooling.org/research/a-brief-history-of-homeschooling. Acesso em: 19 ago. 2019.

ESCOLA SEM PARTIDO. Apresentação. 2019. Disponivel em: https://www.escolasempartido.org/quem-somos/. Acesso em: 20 ago. 2019.

ESPINOSA B. R. S.; QUEIROZ, F. B. Campanuci. Breve análise sobre as redes do Escola sem Partido. In: FRIGOTTO, G. (org.). Escola "sem" partido. Esfinge que ameaça a educação e a sociedade brasileira. Rio de Janeiro: LPP/UERJ, 2017. p. 49-62. 
FREITAS, N. A. de; BALDAN, M. Dossiê Escola Sem Partido e Formação Humana. Apresentação. Fênix Revista de História e Estudos Culturais, ano XIV, v. 14, n. 1, p. 1-8, jan./jun. 2017.

FRIGOTTO, G. (org.). Escola "sem" partido. Esfinge que ameaça a educação e a sociedade brasileira. Rio de Janeiro: LPP/UERJ, 2017.

GIDDENS, A.; SUTTON, P. W. Conceitos essenciais da sociologia. Tradução: Cláudia Freire. 2. ed. rev. São Paulo: Editora UNESP, 2017.

GILL, R. Análise de discurso. In: BAUER, M. W.; GASKELL, G. Pesquisa qualitativa com texto, imagem e som: um manual prático. 8. ed. Petrópolis: Vozes, 2010. p. 244-270.

GORZONI, S. de P.; DAVIS, C. 0 conceito de profissionalidade docente nos estudos mais recentes. Cadernos de Pesquisa, São Paulo, v. 47, n. 166, p. 1396-1413, dez. 2017.

HISTORY of creationism. Wikipedia, [201-2]. Disponivel em: https://en.wikipedia.org/wiki/History_of_creationism. Acesso em: 19 ago. 2019.

HUNTER, J. D. Cultural wars. The struggle to define America. New York: Basic Books, 1991.

INTERNATIONAL CENTER FOR HOME EDUCATION RESEARCH. About ICHER. [S. l]: ICHER, [201-]. Disponivel em: http://www.icher.org/icher.html. Acesso em: 19 ago. 2019.

MARTINS, L. S. R. A educação na sombra: contratação de empresas de acompanhamento escolar como estratégia educativa de famílias das camadas médias. 2019. Dissertação (Pós-Graduação em Educação) - Universidade Federal de Minas Gerais, Belo Horizonte, 2019.

NOGUEIRA, M. A. Classes médias e escola: novas perspectivas de análise. Currículo sem Fronteiras, v. 10, n. 1, p. 213-231, jan./jun. 2010.

OLIVEIRA, E. Projeto de lei que pretende regulamentar a educação domiciliar no Brasil prevê provas anuais e cadastro no MEC. G1 Educação, 11 abr. 2019. Disponivel em: https://gl.globo.com/educacao/noticia/2019/04/11/governo-divulga-projeto-de-lei-que-pretende-regulamentar-a-educacao-domiciliar-no-brasil.ghtml. Acesso em: 19 ago. 2019.

OLIVEIRA, R. L. P. de; BARBOSA, L. M. R. B. 0 neoliberalismo como um dos fundamentos da educação domiciliar. Pro-posições, v. 28, n. 2, p. 93-212, maio/ago. 2017.

RAMALHO, R. STF decide que pais não podem tirar filhos da escola para ensiná-los em casa. G1 Política, 12 set. 2018. Disponível em: https://gl.globo.com/politica/noticia/2018/09/12/stf-decide-que-pais-nao-podem-tirar-filhos-da-escola-para-ensina-los-em-casa.ghtml. Acesso em: 3 set. 2019.

RAY, B. D. Research facts on homeschooling. IS. l.: National Home Education Research Institute, 2015. Disponivel em: https://eric.ed.gov/?̨id=ED556234. Acesso em: 3 set. 2019. 
RIBEIRO, P. S. 0 advento do neopentecostalismo no Brasil. Brasil Escola, [201-2]. Disponivel em: https:// brasilescola.uol.com.br/sociologia/o-advento-neopentecostalismo-no-brasil.htm. Acesso em: 3 set. 2019.

SCHOOL CHOICE. Wikipedia, [201-2]. Disponível em: https://en.wikipedia.org/wiki/School_choice. Acesso em: 3 set. 2019.

SPAUTZ, D. Disque-denúncia contra professores de Santa Catarina tem nova derrota no STF. NSC Total, 3 set. 2019. Disponível em: https://www.nsctotal.com.br/colunistas/dagmara-spautz/disque-denuncia-contra-professores-de-santa-catarina-tem-nova-derrota-no. Acesso em: 3 set. 2019.

VASCONCELOS, M. C. C. Educação na casa: perspectivas de desescolarização ou liberdade de escolha? Pro-posições, v. 28, n. 2, p. 122-140, maio/ago. 2017.

VIEIRA, A. de H. P. "Escola? Não, obrigado": um retrato da homeschooling no Brasil. 2012. Monografia (Graduação em Ciências Sociais, habilitação em Sociologia) - Universidade de Brasília, Brasilia, DF, 2012.

YOUNG, M. Para que servem as escolas? In: PEREIRA, M. Z. da C.; CARVALHO, M. E. P. de; PORTO, R. de C. C. (org.). Globalização, Interculturalidade e Currículo na Cena Escolar. Campinas: Alínea, 2009. p. 37-54.

Endereço para correspondência: Rua lngá, 194, apto. 101, Manaíra, João Pessoa, Paraíba, Brasil; mepcarv@gmail.com

Roteiro, Joaçaba, U. 45, p. 1-28, jan./ dez. 2020 | e23222 |E-ISSN 2177-6059 
